\title{
INSTYTUCJONALNE I KULTUROWE PODEJŚCIE DO PROCESU MEDIATYZACII POLITYKI
}

\author{
INSTITUTIONALIST AND CULTURALIST APPROACH \\ TO THE PROCESS OF MEDIATIZATION OF POLITICS
}

Łukasz Wojtkowski*

\begin{abstract}
ABSTRAKT
Artykuł zawiera teoretyczną propozycję analizy procesu mediatyzacji polityki w ujęciu instytucjonalnym i kulturowym. Dotychczasowe badania procesów mediatyzacji polityki ograniczają się głównie do śledzenia wzajemnych relacji aktorów medialnych i politycznych, nie skupiając się na roli odbiorców komunikacji politycznej. W celu przełamania tego podejścia proponuję upodmiotowić odbiorców w procesie badania mediatyzacji polityki. $\mathrm{W}$ tym ujęciu mediatyzacja polityki rozumiana będzie jako proces transformacji komunikacji politycznej wywołany zmianami w mediach, platformach mediów społecznościowych i technologicznej infrastrukturze komunikacji. Dlatego, z jednej strony, aby wychwycić jak formowana jest aktywna publiczność i jak wchodzi w relacje $\mathrm{z}$ organizacjami medialnymi oraz politycznymi, wykorzystuję założenia teorii strukturacji w zakresie mediatyzacji. Z drugiej strony, dokładam podejście krytyczne, które pozwala na ciągłe śledzenie jak powstaje władza mediów,
\end{abstract}

The paper concerns a theoretical approach to the process of mediatization of politics explained within the framework of the institutionalist and culturalist studies of mediatization. I argue that the contemporary analyses of mediatization of politics limit the process to mutual relations between media and politics with no further consideration of the audience. To bypass this clinch, I propose to study political communication processes as if the audience matters. In that sense, mediatization of politics is perceived as a transformation process of political communication effected by changes in mass media, social media platforms and technology. On the one hand, I use structuration theory in terms of mediatization to capture how the active audience is shaped and how it interacts with the media and political institutions in a highly media-saturated environment. It enables to observe how media practices are transformed into stable agency structure dyad framed as a social institution. On the other hand, I add critical tackle that allows for

* Uniwersytet Mikołaja Kopernika w Toruniu, Wydział Politologii i Studiów Międzynarodowych. 
jakie są jej komponenty, w jaki sposób następują jej przepływy, zakłócenia i przejęcia.

Słowa kluczowe: mediatyzacja polityki, instytucjonalizacja, władza mediów, sprawczość, struktura constant tracking of how media power is created, what dimensions it has, and when the processes of media powers' flows, interruptions, and shifts occur.

Keywords: mediatization of politics, institutionalisation, media power, agency, structure

\section{WPROWADZENIE}

Proces mediatyzacji od ponad dwudziestu lat zajmuje ważne miejsce w pracach z zakresu nauk politycznych i medioznawstwa. Na polskim odcinku badań szczególnego miejsca doczekały się prace z zakresu mediatyzacji polityki (zob.: Adamik-Szysiak, 2015, 2016; Kolczyński, Mazur, Michalczyk, 2009; Wojtkowski, 2012a; 2012b). Jednak rozwój koncepcji mediatyzacji polityki stracił na impecie. Dlatego warto zastanowić się, co należy zrobić, aby wykorzystać potencjał drzemiący w analizach procesów mediatyzacji polityki. W tym celu zastosuję dwie perspektywy badawcze, które od wielu lat pozostają w pozornej sprzeczności metodologicznej i teoretycznej. Rozważania z zakresu instytucjonalnej perspektywy mediatyzacji - głównej osi teoretycznej tego tekstu - zostaną uzupełnione o analizy z obszaru studiów kulturowych. Choć wskazana wcześniej antynomia obu podejść jest myląca, to nadal relatywnie rzadko spotyka się prace z zakresu mediatyzacji łączące oba stanowiska.

Wychodząc od jednoczesnego zastosowania obu perspektyw, zakładam, że (1) proces mediatyzacji polityki wymaga rekonceptualizacji i uwypuklenia roli odbiorcy komunikacji politycznej; (2) perspektywa instytucjonalna pozwala na analizę relacji komunikacyjnej w procesie strukturacji instytucji społecznych, politycznych i medialnych; (3) perspektywa krytyczna daje możliwość badania relacji władzy pomiędzy wspomnianymi „aktorami”. Te założenia odnoszą się do hipotez: (1) w mediatyzacji polityki praktyki medialne odbiorców przyjmują w procesie strukturacji postać aktywnej publiczności; (2) władza mediów posiada trzy wymiary: symboliczny, technologiczny i ekonomiczny; (3) aktywna publiczność adaptuje mechanizmy władzy mediów w wymiarze symbolicznym i technologicznym; (4) nie ma możliwości adaptacji wymiaru ekonomicznego władzy mediów. 


\section{DOMINUJĄCE PERSPEKTYWY MEDIATYZACJI POLITYKI}

Pomimo tego, że badania mediatyzacji polityki dały początek analizom procesów mediatyzacji (zob.: Mazzoleni, Schulz, 1999; Schulz, 2004; Strömbäck, 2008; 2011; Strömbäck, Esser, 2014a; 2014b), należy dostrzec spowolnienie rozwoju samej koncepcji, jednowymiarowość współczesnych analiz oraz, w wielu miejscach, ich przyczynkarski charakter. Warto się zastanowić nad powodami takiego stanu rzeczy oraz nad możliwościami przełamania wspomnianych trudności (zob.: Brodzińska-Mirowska, Wojtkowski, 2017, w druku). Na pierwszy plan wysuwa się rozdźwięk między teorią mediatyzacji polityki a projektami badań. Silny nacisk na empirię powoduje niekiedy oderwanie od teoretycznych koncepcji mediatyzacji polityki, co przekłada się na jakość projektów, które stają się fragmentaryczne, skupione na pojedynczych przykładach uzupełnianych o analizy porównawcze. Badania ogniskują się na linearnym opisie relacji między mediami a polityką. Przez co sam proces komunikowania politycznego zostaje uproszczony do związku dwóch „aktorów”, pomijając jeden z najważniejszych elementów, czyli odbiorców komunikacji politycznej (Esser, Matthes, 2013; Witschge, 2014). Taka jednowymiarowość owocuje przewagą studiów przypadku z zakresu kampanii wyborczych, marketingu politycznego, komunikacji politycznej online, w których bada się proces wzajemnej „kolonizacji” mediów i polityki oraz relacje między logikami mediów i polityki (zob. też: Lundby, 2009; Strömbäck, 2008; Strömbäck, Esser, 2014a, 2014b).

Dominujące podejścia w sposób bardzo złożony opisują relacje mediów i polityki, ale pomijają jednocześnie znaczenie odbiorców w tych procesach. Przykładem mogą być klasyczne prace Winfrieda Schulza (Mazzoleni, Schulz, 1999; Schulz, 2004, 2006), Jespera Strömbäcka $(2008,2011)$ i Strömbäcka w duecie z Frankiem Esserem (2014a, 2014b). Schulz zauważa proces transformacji społecznej, jakiego dokonują media (cztery wymiary zmiany społecznej), ale aplikuje go do analizy selekcji, produkcji, transmisji informacji politycznych przez media (por.: Schulz, 2004; 2006). Z kolei Strömbäck, wyznaczając ramy czasowe dla procesu mediatyzacji polityki (2008), wyróżnił cztery fazy procesu. Co prawda w tle każdej z faz majaczy społeczeństwo i odbiorcy informacji politycznej, ale traktowani są oni jako stosunkowo bierny element układanki, wokół którego toczy się starcie logik medialnych i politycznych. Ciekawie prezentuje się podejście Essera i Jörga Matthesa (2013), którzy wyróżniają cztery obszary mediatyzacji polityki: na poziomie treści medialnej, aktorów, organizacji i odbiorców komunikacji politycznej. Jednak znów upraszczają proces mediatyzacji polityki 
do relacji logik ${ }^{1}$. Podsumowaniem tych założeń może być zaproponowana przez Strömbäcka i Essera definicja mediatyzacji polityki (2014b): „długotrwały proces, podczas którego wzrosło znaczenie i oddziaływanie mediów na proces, instytucje, organizacje i aktorów politycznych". W tym ujęciu znów zanika społeczeństwo i publiczność. Wydaje się oczywistym, że większość procesów komunikacji politycznej nie jest ograniczona do gry dwóch aktorów, ponieważ każdemu z nich zależy na maksymalizacji zysku. W przypadku mediów zysk mierzony jest w postaci przychodu i zasięgu publiczności. W przypadku polityki - załóżmy idealistycznie - w postaci zdobycia i utrzymania władzy. W każdym razie zysk przeliczany jest na zasięg społeczny (publiczność, wyborcy), który uzależniony jest od postaw politycznych społeczeństwa, wynikających w dużym stopniu z praktyk odbiorczych.

\section{INSTYTUCJONALNA I KULTUROWA PERSPEKTYWA MEDIATYZACJI POLITYKI}

Aby przełamać te trudności, zastosuję koncepcję mediatyzacji polityki opartą nie na aparacie wyjaśniającym komunikowania politycznego, a na, z jednej strony, instytucjonalnej perspektywie mediatyzacji oraz, z drugiej strony, na teorii kulturowej. Pierwsza z nich jest jedną z najlepiej zoperacjonalizowanych w mediatyzacji (zob.: Bolin, 2014; Couldry, Hepp, 2013; Jensen, 2013; Lundby, 2014). Jej głównym twórcą jest Stig Hjarvard, który w cyklu prac (Hjarvard, 2008, 2013, 2014a, 2014b) analizował instytucjonalne konsekwencje roli mediów w społeczeństwie. Mediatyzacja „oznacza nie tylko, że media odgrywają rolę w ich własnym zakresie, ale że zyskały status niezależnej instytucji i dostarczają środków, dzięki którym komunikują się inne instytucje społeczne i aktorzy" (Hjarvard, 2008). Hjarvard, opierając swoją koncepcję na pracach Anthonego Giddensa z zakresu strukturacji społecznej (1984), analizuje mechanizmy instytucjonalizacji mediów i ich relacji z innymi instytucjami społecznymi, skupiając się na wzorcach praktyk społecznych formułujących sprawczość (agency) i strukturę (structure) instytucji, oraz na tym, jaką rolę odgrywają w tych procesach media. W tym ujęciu media katalizują zmiany kulturowe i społeczne, a inne instytucje stają się w pewnym zakresie zależne od mediów i ich przemian.

1 Wyczerpująca dyskusja tych podejść (por.: Brodzińska-Mirowska, Wojtkowski, 2017). 
Można zatem wnioskować, że każda instytucja społeczna posiada wewnętrzną logikę - zasoby i reguły, decydujące o strukturze i sprawczości instytucji - która poprzez mechanizm komunikacji wchodzi w interakcje z logikami innych instytucji. Zatem mediatyzacja opisuje długotrwałe procesy transformacji społecznej spowodowane zmianami w mediach. Siłą napędową w tym procesie są instytucje medialne, na co wpływa wymiar symboliczny działania mediów (o czym dokładniej za chwilę), który przybiera postać władzy symbolicznej (symbolic power) mediów w procesach komunikowania społecznego. Z czasem inne instytucje społeczne, aby być obecnymi w dyskursie społecznym (czy w ogóle widocznymi społecznie), muszą dostosować się do zmian medialnych.

Z kolei kulturowa perspektywa mediatyzacji zajmuje się głównie koncepcjami władzy mediów (media power). Perspektywa ta nie jest spójna, o czym może świadczyć obecność wielu mniejszych obszarów badawczych w jej obrębie: analizy władzy mediów (Asp, 2014; Brodzińska-Mirowska, Wojtkowski, 2017), hegemonii (Block, 2013), kultury popularnej (Fornäs, 2014), subkultur (Encheva, Driessens, Verstraeten, 2013) czy praktyk kulturowych (Kaun, Fast, 2013). Z punktu widzenia procesu mediatyzacji polityki warto poświęcić czas na analizę kluczowej kategorii kulturowych teorii mediów: władzy mediów. Biorąc za punkt wyjścia założenia Nicka Couldry’ego, władza mediów oznacza koncentrację zdolności do symbolicznej „konstrukcji rzeczywistości”, nie oznacza automatycznej dominacji „dużych aktorów” (media masowe) nad „małymi aktorami” (publiczność, odbiorcy mediów; Couldry, 2001), ale musi podlegać ciągłej renegocjacji. Wraz z postępującym procesem mediatyzacji, władza mediów zaczyna dominować nad innymi aktorami oraz instytucjami społecznymi zarówno na poziomie odbiorców, jak i treści medialnych (Asp, 2014). Aby uchwycić faktyczną władzę mediów i jej znaczenie w instucjonalnym procesie mediatyzacji należy położyć nacisk na miejsca, w których władza mediów jest renegocjowana, gdzie następują jej przepływy (flows), zakłócenia (interuptions) i zmiany (shifts). Czyli w miejscach, w których odbiorcy stykają się z mediami i przekazem medialnym. Innymi słowy, na poziomie procesów komunikacji politycznej należy badać mediatyzację polityki tak, aby odbiorczość (the audience, reception) była kluczowym elementem procesu (Witschge, 2014) oraz aby uchwycić wymiar symboliczny, technologiczny i ekonomiczny władzy mediów.

Wykorzystując aparat kulturowy i instytucjonalny dla analizy mediatyzacji polityki, można obserwować: (a) indywidualne praktyki kulturowe odbiorców mediów (np. przekazów politycznych), (b) proces formowania się publiczności 
medialnej i tworzenia większych grup praktyk odbiorczości, które wchodzą $\mathrm{w}$ relacje władzy z mediami i polityką.

W pierwszym przypadku badaną kategorią będzie praktyka medialna, czyli społeczna praktyka zorientowana na media, którą można scharakteryzować jako zespoły podobnych działań (actions) podejmowanych przez jednostki. Praktyka taka, zdaniem Couldry'ego (2012), jest regularna, społeczna, odpowiada na potrzeby i konstruuje normy. Praktyka medialna wymaga użycia mediów przez jednostki. Jeśli użycie nie jest ograniczone jedynie do praktyk odbiorczych, a uwzględnia publikowanie lub cyrkulowanie treściami, wówczas odbiorcy mediów stają się aktywną publicznością. W procesie mediatyzacji polityki przybiera to postać trzech niewykluczających się wzorców: praktyka medialna może być w całości zorientowana na użycie technologii komunikacyjnej, która zastąpiła wcześniejsze narzędzie komunikowania (np. użycie Messengera lub grup na Facebooku zamiast bezpośredniej rozmowy w celach organizacji protestów); praktyka medialna jest komplementarna do wcześniejszych praktyk społecznych (np. używanie Twittera i przekazów telewizyjnych w celu obserwowania procesu politycznego); nowa praktyka medialna jest wzmocniona wcześniejszą praktyką medialną (np. second screening). Tak rozumiana praktyka medialna pozwala uchwycić sposób, w jaki aktywni odbiorcy treści medialnych wchodzą we wzajemne interakcje z mediami i polityką na poziomie mikro. Jednak kategoria praktyki medialnej jest niewystarczająca do uchwycenia szerszej perspektywy transformacyjnej, ponieważ praktyki medialne mogą się od siebie znacznie różnić (przez co tworzą wielkie heterogeniczne zbiory) oraz zależą od innych elementów układanki społecznej (struktury społecznej czy relacji władzy).

Dlatego - w drugim przypadku - analiza procesu mediatyzacji polityki powinna obrazować kształtowanie się instytucji aktywnej publiczności medialnej, które ma miejsce w wysyconym medialnie środowisku komunikacji politycznej. Odwołując się do podejścia instytucjonalnego, analiza obejmuje proces transformacji instytucji społecznych pod wpływem instytucji medialnych. Jeśli wyjdziemy z założenia, że we współczesnych procesach komunikacji politycznej dużą rolę odgrywa aktywna publiczność, która wykorzystując technologie komunikacyjne, wchodzi w interakcje zarówno z dziennikarzami i politykami, to warto zastanowić się, czy ta publiczność jest w stanie stworzyć instytucję społeczną, która może aktywnie oddziaływać przy pomocy technologii na proces polityczny i medialny? Wspomniałem już, powołując się na Hjarvarda, że uchwycenie instytucjonalizacji na poziomie mezo daje możliwość szerszej analizy procesu mediatyzacji polityki. Przydatna jest tu siatka kategorii wyko- 
rzystana przez Giddensa (1984), który instytucjom społecznym przypisuje posiadanie struktury wyposażonej w reguły (rules) - techniki i procedury wykorzystywane do reprodukcji praktyk społecznych - i zasoby (resources) materialna lub symboliczna infrastruktura praktyk społecznych. W przypadku aktywnej publiczności medialnej, u której można wyróżnić zespół podobnych praktyk medialnych (np. regularna komunikacja na tematy polityczne na Twitterze), zasobem będzie infrastruktura komunikacyjna (np. aplikacje mobilne, komputery, konta na platformie, systemy sygnifikacji udostępniane przez platformę i użytkowników), stanowiąca przestrzeń komunikacyjną, w ramach której występują określone reguły. Te z kolei mogą być nieformalne (np. zasady używania określonych hashtagów, blokowania botów, użytkownicy warci obserwowania) lub formalne (już samo zaakceptowanie regulaminu Twittera). Co więcej, niezależni wcześniej użytkownicy (członkowie publiczności medialnej) zamieniają w ten sposób nieregularną praktykę medialną w systematyczną, ustrukturyzowaną sprawczość (agency) medialną w ramach struktury instytucji publiczności. Im mocniej publiczność komunikacji politycznej reguluje sprawczość w ramach struktury, tym większe szanse, że przejdzie proces silnej strukturacji i przerodzi się w ruch społeczny. Jest wiele przykładów ruchów, posiadających agendę polityczną, które powstawały w oparciu o podobny schemat przejścia od dynamicznej praktyki medialnej, przez regularną sprawczość medialną, zwieńczoną stabilną strukturą: Indignidos (Movimento 15-M), z którego wywodzi się lewicowa partia Podemos, Occupy Wall Street, Ocupy Movement, Komitet Obrony Demokracji. Przykłady te pokazują, jak wykorzystując zaangażowanie online, można zbudować oddolnie inicjatywę społeczną, która z czasem formalizuje swoje działania i struktury, oddziałuje na agendę medialną oraz polityczną, stając się istotnym elementem krajobrazu politycznego. Niezależnie od stopnia dynamiki, strukturacji i narzędzi działania, wszystkie wskazane ruchy funkcjonują, wykorzystując w znacznym zakresie mechanizmy medialne, ucząc się ich na żywej tkance protestu politycznego.

Jednak sam proces strukturacji publiczności komunikacji politycznej, nawet skrupulatnie śledzony i analizowany, nie wyjaśnia, dlaczego (i w jakich miejscach) można wejść w relację z władzą mediów i renegocjować ją. Dlatego należy skupić się na miejscach przepływów, zakłóceń i zmian władzy mediów. Odwołałem się wcześniej do koncepcji Couldry’ego, który zakładał, że władza mediów jest pewnego rodzaju symboliczną relacją, czy jak to ujmuje Manuel Castells, zdolnością relacyjną „(...) która umożliwia aktorowi społecznemu wywieranie asymetrycznego wpływu na decyzje innych aktorów społecznych 
w sposób sprzyjający umacnianiu jego woli, interesów wyznawanych wartości" (Castells, 2013). Analizując proces mediatyzacji polityki, warto zadać dwa pytania: jakie są wymiary władzy mediów? i jak można ją renegocjować?

Pierwszym jest wymiar symboliczny (Couldry, 2001; Couldry, Curran, 2003). W dyskursywnej przestrzeni komunikacji polityki to media konstruują rzeczywistość polityczną, decydując o znaczeniu i przebiegu komunikacji między poszczególnymi aktorami. Dzieje się tak, ponieważ media są instytucją o dużym potencjale sygnifikacji i wykorzystując podstawowe mechanizmy oddziaływania w dyskursie, tworzą symboliczny wymiar władzy kreowania świata społecznego (Schrøder, Phillips, 2016). Media już przez samą swoją obecność w przestrzeni komunikacji politycznej oddziałują na poziomie symbolicznym na przebieg procesów komunikacyjnych. Ta swoista geografia mediów, sposób ich rozmieszczenia w krajobrazie politycznym, oddziałuje na dostęp aktorów społecznych i politycznych do tworzonego przez media systemu znaczeń hegemonicznych. Taka charakterystyka oddaje modus operandi mediów tradycyjnych, ale zaburza możliwość analizy mediów nowych.

Dlatego drugim wymiarem władzy mediów jest wymiar technologiczny związany ze sposobami wykorzystania technologii komunikacyjnych w procesach kształtowania aktywnej publiczności komunikacji politycznej. Technologia z samej obecności daje jedynie iluzoryczną możliwość zmiany w relacji władzy. Dopiero jej aktywne wykorzystanie umożliwia oddziaływanie na proces mediatyzacji polityki. Przy czym warto zaznaczyć, że nie chodzi o technologię produkcyjną i transmisyjną wykorzystywaną przez media masowe, ale o infrastrukturę technologiczną dostarczaną przez korporacje internetowe. Dzięki procesowi apropriacji technologii publiczność medialna może się w pełni uaktywnić i być widoczną na poziomie dyskursu medialnego. Podobne narzędzia w rękach organizacji politycznych i polityków również wpływają na ich obecność medialną (z pewnością w zakresie ilościowym). Jak pokazywałem na przykładzie praktyk medialnych, wykorzystanie aplikacji mobilnych czy mediów społecznościowych pozwala na szybkie organizowanie poszczególnych działań (np. przez grupy na Facebooku), agregowanie podobnych tematów (np. określone hashtagi) czy koordynację i spójność narracji medialnej. Publiczność uczy się od mediów tego, co i jak robić, aby być widoczną na poziomie narracji medialnej. Dzieje się tak $\mathrm{w}$ procesie internalizacji logik medialnych, który nieustannie przebiega w relacji mediatyzacyjnej, dzięki czemu publiczność i politycy wychwytują mechanizm decydujący o wpływaniu na agendę medialną. 
Należy jednak pamiętać, że wymiar technologiczny władzy mediów jest w pełni uzależniony od wymiaru ekonomicznego, ponieważ wspomniane technologie dostarczane są przez największe światowe korporacje, które decydują o bezpośrednim dostępie do platform społecznościowych. Dzięki wykorzystywanym algorytmom Facebook, Google czy Twitter determinują proces tworzenia, cyrkulacji i komodyfikacji danych, który oddziałuje na wszystkich trzech aktorów mediatyzacji polityki. Jeśli nałożymy na tę relację narzędzia ekonomii politycznej mediów, otrzymamy obraz procesu, w którym wspomniane korporacje wyznaczyły kierunek i ramy rozwoju komunikacji politycznej nie tylko w zakresie dostępu do platform, ale też przez mechanizm funkcjonowania w ich mikrosystemie. Złożone mikrosystemy platform społecznościowych są w stanie budować nie tylko totalizującą strukturę socjoekomoniczną (struktura właścicielska, model biznesowy, zarządzanie) i technologiczną (relacje technologii, użytkowników i treści; zob.: van Dijck, 2013), ale też wyznaczyć reguły komunikacyjne działające poza nimi. Co ważne z punktu widzenia prezentowanego w tekście podejścia do procesu mediatyzacji polityki, reguły te dotykają w równym zakresie mediów, polityki i aktywnych odbiorców.

Wydaje się, że przy obecnym rozwoju korporacji platform społecznościowych i technologii komunikacyjnych, trzy wymiary władzy mediów - symboliczny, technologiczny, ekonomiczny - mogą podlegać ciągłej renegocjacji, która daje możliwość przesunięcia części zasobów w relacji władzy na korzyść aktywnej publiczności. Gdzie szukać renegocjacji władzy mediów w analizach procesów mediatyzacji polityki? Odpowiedzi dostarcza badanie przepływów władzy (media power flows), czyli miejsc, gdzie ludzie (publiczność) wchodzą w interakcje $\mathrm{z}$ procesem medialnym (Couldry, 2001). Jeśli w trakcie takiego procesu bierna publiczność upodmiotowia się, przekształca się w aktywnego odbiorcę procesu komunikacji politycznej i może skutecznie zakłócić przepływ władzy (interruption). Gdy takie zakłócenie ma charakter stały i pozwala wypracować nowy wzorzec oddolnego oddziaływania medialnego aktywnej publiczności, możemy mówić o zmianie władzy mediów (media power shift). W praktyce proces ten może przybrać wiele form, a wcześniej użyte przykłady przekształcenia dynamicznej praktyki medialnej w zwarte ruchy społeczne obrazują jego pełną rozciągłość. 


\section{PODSUMOWANIE}

Na koniec warto podkreślić, że wykorzystanie mechanizmu nadawania znaczenia przez media (symboliczny wymiar władzy mediów) jest kluczowe dla próby podjęcia zmiany znaczeń dominujących $\mathrm{w}$ dyskursie medialnym, chociażby w zakresie sentymentu narracji mediów i organizacji politycznych o danym ruchu (aktywnej publiczności). Zakłócenie dominującego znaczenia byłoby jednak niemożliwe bez internalizacji logiki działania mediów (np. w zakresie widowiskowości i sensacyjności przygotowanego protestu). Dzięki temu publiczność może narzucić swój sposób narracji medialnej, który będzie przez nadawców rozprzestrzeniany dalej. Zakłócenie takie nie byłoby możliwe bez dostępu do infrastruktury technologicznej dostarczonej przez zorganizowanych nadawców medialnych i - a może przede wszystkim - przez platformy mediów społecznościowych. W ten sposób aktywna publiczność internalizuje nie tylko logikę mediów, ale też logikę technologiczną, wiedząc, jakie reguły i zasoby decydują o widoczności w środowisku internetowym. Na tym kończy się zdolność internalizacji, którą nabył ruch społeczny. Nie jest bowiem w stanie, przynajmniej nie bez straty dla siebie, zinternalizować wymiaru ekonomicznego władzy mediów, ponieważ każde działanie ruchu nastawione na zmianę wymiaru symbolicznego władzy mediów przy wykorzystaniu technologii musi zawierać komponent maksymalizacji zysku ekonomicznego zorganizowanych nadawców medialnych i, przede wszystkim, korporacji platform społecznościowych. Jednak to już temat na kolejne rozważania.

\section{BiBLIOGRAFIA:}

Adamik-Szysiak, M. (red.). (2015). Mediatyzacja komunikowania politycznego. W kręgu badań politologicznych i medioznawczych. Lublin: Wydawnictwo UMCS.

Adamik-Szysiak, M. (red.). (2016). Polityka w zmediatyzowanym świecie. Perspektywa politologiczna i medioznawcza. Lublin: Wydawnictwo UMCS.

Asp, K. (2014). Mediatization: Rethinking the Question of Media Power. W: K. Lundby (red.), Mediatization of Communication. Handbooks of Communication Science (s. 349-373). Boston: De Gruyter Mounton.

Block, E. (2013). A Culturalist Approach to the Concept of the Mediatization of Politics: The Age of "Media Hegemony". Communication Theory, 23(3), s. 259-278. DOI: http://doi.org/10.1111/comt.12016. 
Bolin, G. (2014). Institution, Technology, World: Relationships Between the Media, Culture, and Society. W: K. Lundby (red.), Mediatization of Communication. Handbooks of Communication Science (s. 175-197). Boston: De Gruyter Mounton.

Brodzińska-Mirowska, B., Wojtkowski, Ł. (2017). Is There Any Future for Research on the Mediatization of Politics? W: O. Driessens, A. Hepp, S. Hjarvard, G. Bolin (red.), Dynamics Of Mediatization. London: Palgrave Macmillan. DOI: http://doi. org/10.1007/978-3-319-62983-4_7.

Castells, E. (2013). Władza komunikacji. Warszawa: Wydawnictwo Naukowe PWN.

Couldry, N. (2001). The Place of Media Power: Pilgrims and Witnesses of the Media Age. London: Routledge.

Couldry, N. (2012). Media, Society, World. Cambridge: Polity.

Couldry, N., Curran, J. (2003). Contesting Media Power. Oxford: Rowman \& Littlefield.

Couldry, N., Hepp, A. (2013). Conceptualizing Mediatization: Contexts, Traditions,Arguments. Communication Theory, 23(3), s. 191-202. DOI: http://doi.org/10.1111/ comt.12019.

Encheva, K., Driessens, O., Verstraeten, H. (2013). The Mediatization of Deviant Subcultures: An Analysis of the Media-Related Practices of Graffiti Writers and Skaters. MedieKultur Journal of Media and Communication Research, 29(54), s. 18-25. DOI: http://doi.org/10.7146/mediekultur.v29i54.7349.

Esser, F., Matthes, J. (2013). Mediatization Effect of Political News, Political Actors, Political Decision and Political Audience. W: H. Kriesi, S. Lavenex, F. Esser, J. Matthes, M. Bühlmann, D. Bochsler (red.), Democracy in the Age of Globalization and Mediatization, (s. 177-201). London: Palgrave Macmillan.

Fornäs, J. (2014). Mediatization of Popular Culture. W: K. Lundby (red.), Mediatization of Communication. Handbooks of Communication Science (s. 483-504). Boston: De Gruyter Mounton.

Giddens, A. (1984). The Constitution of Society. Cambridge: Polity.

Hjarvard, S. (2008). The Mediatization of Society. Nordicom Review, 29(2), s. 105-134. Hjarvard, S. (2013). The Mediatization of Culture and Society. London: Routledge.

Hjarvard, S. (2014a). From Mediation to Mediatization: The Institutionalization of New Media. W: F. Krotz, A. Hepp (red.), Mediatized Worlds Culture and Society in a Media Age. London: Palgrave Macmillan.

Hjarvard, S. (2014b). Mediatization and Cultural and Social Change: An Institutional Perspective. W: K. Lundby (red.), Mediatization of Communication. Handbooks of Communication Science (s. 199-226). Boston: De Gruyter Mounton.

Jensen, K.B. (2013). Definitive and Sensitizing Conceptualizations of Mediatization. Communication Theory, 23(3), s. 203-222. DOI: http://doi.org/10.1111/comt.12014. Kaun, A., Fast, K. (2013). Mediatization of Culture and Everyday Life. Research report for Riksbanken Jubileumsfond.

Kolczyński, M., Mazur, M., Michalczyk, S. (red.). (2009). Mediatyzacja kampanii politycznych. Katowice: Wydawnictwo Uniwersytetu Śląskiego.

Lundby, K. (2009). Media Logic: Looking for Social Interaction. W: K. Lundby (red.), Mediatization: Concept, Changes, Consequences (s. 101-119). New York: Peter Lang. 
Lundby, K. (red.). (2014). Mediatization of Communication. Handbooks of Communication Science. Boston: De Gruyter Mouton.

Mazzoleni, G., Schulz, W. (1999). Mediatization of Politics: A Challenge for Democracy? Political Communication, 16(3), s. 247-261.

Schrøder, K.C., Phillips, L. (2016). Complexifying Media Power: A Study of the Interplay Between Media and Audience Discourses on Politics. Media, Culture \& Society, 29(6), s. 890-915. DOI: http://doi.org/10.1177/0163443707081693.

Schulz, W. (2004). Reconstructing Mediatization as an Analytical Concept. European Journal of Communication, 1(19), s. 87-101.

Schulz, W. (2006). Komunikacja polityczna. Koncepcje teoretyczne i wyniki badań empirycznych na temat mediów masowych w polityce. Kraków: WUJ.

Strömbäck, J. (2008). Four Phases of Mediatization: An Analysis of the Mediatization of Politics. The International Journal of Press/Politics, 13 (3), s. 228-246.

Strömbäck, J. (2011). Mediatization and Perceptions of the Media’s Political Influence. Journalism Studies, 12(4), s. 423-439.

Strömbäck, J., Esser F. (2014a). Mediatization of Politics: Towards a Theoretical Framework. W: J. Strömbäck, F. Esser (ed.), Mediatization of Politics: Understanding the trans-formation of Western democracies (s. 3-28). Basingstoke: Palgrave Macmillan.

Strömbäck, J., Esser, F. (2014b). Mediatization of Politics. Transforming Democracies and Reshaping Politics. W: K. Lundby (red.), Mediatization of Communication. Handbooks of Communication Science (s. 375-397). Boston: De Gruyter Mounton. van Dijck, J. (2013). The Culture of Connectivity. Oxford: Oxford University Press.

Witschge, T. (2014). Passive Accomplice or Active Disruptor. Journalism Practice, 8(3), s. 342-356. DOI: http://doi.org/10.1080/17512786.2014.889455

Wojtkowski, Ł. (2012a). Mediatization of Politics During U.S. Presidential Election 2008. Kultura i Edukacja, 6(92), s. 109-124.

Wojtkowski, Ł. (2012b). Mediatyzacja polityki. Przypadek amerykańskiej kampanii prezydenckiej 2008. Toruń: Wydawnictwo Naukowe UMK. 